\title{
Editorial Introduction: Traversing the Mosaic of 'Community, Development and Welfare' Experiences
}

\author{
M. Rezaul Islam ${ }^{1}$ (D) - Niaz Ahmed Khan ${ }^{2}$ \\ Accepted: 9 October 2020 / Published online: 15 October 2020 \\ (C) Springer Nature Switzerland AG 2020
}

We take this opportunity to introduce the special issue on 'Community, Development, and Welfare: a Mosaic of Experiences'. The specific focus of this issue is the outcome of the eight selected papers presented in the "International Symposium on Community-Led Social Work Interventions for Sustainable Development" (ISCSD-2020) held on 6th and 7th January 2020 at the Department of Social Administration and Justice, Faculty of Arts and Social Sciences, University of Malaya, Kuala Lumpur, Malaysia. It was a collaboration between the Editors (University of Dhaka) and the Department of Social Administration and Justice, University of Malaya. All of these sleeted papers are original based on field research that highlighted the 'communities, development and welfare' experiences from Bangladesh, Malaysia, Indonesia and Pakistan.

Communities and the associated efforts and initiatives of development with the ultimate goal of ensuring welfare (for all members of the community) are in a state of constant flux and transformation. The whole gamut of ideas, conceptions and practices concerning community, development and welfare is changing in all sorts of ways. Although there was an argument at the turn of last century to the effect that the concept of 'community' had somewhat outlived its usefulness, yet, as Kuecker et al. (2011) astutely notes, 'the use of the word has certainly not diminished in either popular or academic discourse' and there has actually 'been a turn to community in the conditions of global flux and uncertainty'. From an academic perspective, the challenge of capturing and understanding this changing and chequered mosaic of community

M. Rezaul Islam rezauldu@gmail.com

1 Institute of Social Welfare and Research, University of Dhaka, Dhaka, Bangladesh

2 Department of Development Studies, University of Dhaka, Dhaka, Bangladesh experiences in relation to development and welfare remains as daunting as ever.

This special volume reflects our modest effort to contribute to this challenge of understanding and documentation of selected mosaic of community experiences and efforts over the changing landscape. Despite the growing volume of research on the broader subject of 'community studies', any addition is considered important and worthwhile for two simple reasons: given the sheer diversity and uniqueness of community and associated development and welfare experiences, research on this subject can never claim to be exhaustive, and there is always a room for contributing to the relative cavity in knowledge (see Carpenter et al. 2016); and secondly, there have been relatively limited academic efforts to focus and capture the detail and nuances of micro contextual level community life and living in relation to the implications for development and welfare across many locations; such cases and contexts may generate important lessons for both the relevant academic and practicing quarters.

In the above backdrop, this special volume is a collection of research articles focusing on varied dimensions of the broader theme of 'community, development and welfare' across several countries including Bangladesh, Malaysia, Indonesia and Pakistan. The diverse discussions dwell on particular country and community contexts as well as development and welfare practices. The focus of the discussion ranges from climate- and disaster-affected rural communities, through special groups such as youth and the elderly, to migrant communities. Specific development and welfare interventions are highlighted, and a menu of wider policy options and implications is explored.

In addition to its common connotation (of diversity in a complex yet integrated whole), our adoption and use of the term 'mosaic' here is inspired by a few studies especially Bunkers (2003) and Parse (2003). The various communities explored in the studies contained in this Volume are surely distinct enough - with a specific context, a peculiar set of socio-economic and cultural realities to play with and to be played upon, and a unique story to tell. Yet, in the ultimate analysis, we need to see the big picture: '... the 
interconnected of all things ... the fact that community is all that is' (Bunkers 2003:73 original emphasis). This mosaic of lived community as human experience - including the various configurations of beliefs, values, choices and practices 'all-at-once in mutual process with all that is'-is worthy of exploration (Parse 2003).

The articles contained here are intended to help us traverse the mosaic of 'community, development and welfare' experiences across a diverse range of settings and contextual dynamics. The first article M. Rezaul Islam and his colleagues from the Islamic Relief Bangladesh funded study 'Vulnerabilities of river erosion affected coastal communities in Bangladesh: a menu of alternative livelihood options' unravels the nature, forms and manifestations of socio-economic and psychological vulnerabilities of the river erosion affected coastal communities in Bangladesh, and then suggests a number of alternative livelihood options in order to reduce the vulnerabilities. River erosion is a common natural disaster in Bangladesh. The river erosion wreaked havoc on the communities' physical resources, and increased their psychosocial vulnerabilities such as forced displacement, social insecurity, food insecurity, breakdown of socio-cultural bondage and networks, and decreased social esteem. The lack of livelihood options coupled with poor and fragile household conditions contribute to the reduced ability of the communities to cope with the postdisaster problems. The low level of participation of the river erosion affected people in disaster construction, planning and programs results in a weakened state of community resilience which further increases vulnerability in the future. In conclusion, this paper proposed a number of community-led alternative livelihood options, e.g. adoption of innovative production and processing measures, formation of self-help groups, entrepreneurship development, priority basis livelihood options based on local context, and use of indigenous knowledge and skills-based coping strategies.

The second paper 'Smartphone addiction and bonding social capital among university students of youth community in Bangladesh', based on PhD work of Ashek Mahmud and his two Supervisors, examines the effects of smartphone addiction on bonding social capital among the university students in Bangladesh. The main argument of this paper is that the accessibility of online-based smartphone apps alarmingly increases the compulsive use of smartphone mainly among the youth community in Bangladesh. The study investigates that 28 percent of the university students are addicted to the smartphone which has greater impacts on their primordial social relation as well as bonding social capital that weakens attachment to their family, close friends and relatives, despite having more communicational and interactional benefits from them. The addictive use of smartphone reduces emotional sharing, interior intimacy and responsibility toward the nearest one, but these adverse effects are highly predicted by the adaptive dysfunctions as social symptoms and by the psychological state of feeling panic and anxious without a smartphone. The third paper "Challenges of faith-based NGO intervention in community development: a case study in Bangladesh', based on PhD work of Shofiqur Rahman Chowdhury and his two Supervisors, reports the strengths and challenges of a faith-based non-governmental organization (Islamic Relief Worldwide) in community development from the north-western region of Bangladesh. This paper argues that this faith-based non-governmental organization has made significant contributions in providing services to the ultra-poor without discrimination, offering flexible "pressure-free" loans and developing a sense of community ownership. Within this spectrum, this study found a number of challenges in the community development efforts such as continuation of the provision of interest-free loans, sustaining community-based organizations, labeling of proselytization and deficient implementation mechanisms.

In the fourth paper 'Community-based interventions for vulnerable women: A case of Bangladesh Legal Aid and Services Trust', Md Fakhrul Alam presents a case study of the Bangladesh Legal Aid and Services Trust (BLAST) in Sylhet, Bangladesh. This paper attempts to unveil the reasons behind seeking help of the victimized women from this agen$\mathrm{cy}$, its intervention strategies and the actual outcome. The BLAST tries to solve the problem of domestic violence or family conflicts through mediation meetings involving community leaders and relatives of complainants and defendants, negotiation, discussion and counseling. If it fails, the agency then helps a victim lodge a case in the court. Most of the service seekers are satisfied with its interventions. A strong community involvement makes it easier to reach a consensus. Conversely, some cases could not be resolved due to the noncooperation of husbands, relatives and community leaders. The fifth paper 'Patterns of living environment among itinerant elderly community in Malaysia', based on $\mathrm{PhD}$ work Aqsa Qandeel and her Supervisor, explore the life stories of the itinerant elderly in shelter homes and vagrancy by the series of semi-structured interviews with fourteen folks in Kuala Lumpur, Malaysia. This paper disclosed that although there are variations in the living patterns and living environment at the care homes and public places, the destitute elderly's mental condition matched to a great extent because they were in the same phase of life. The study recommends the establishment of temporary residences for elderly living in the streets to improve their health, hygiene and security and shelter facility along with the provision of some form of privacy in sheltered institutions and panopticon instead of being left homeless to respect their dignity and independence.

In the sixth paper 'Emotional entanglement and community empowerment of transnational migrants' families: A crosssectional study in Malaysia and Indonesia', Anggaunita Kiranantika and her colleague explore the idea of economicdriven migration that implies motion and change, as well as 
gendered and social structures that impact upon the experiences of migrant family members and community-based support in the home country. This paper further highlights discussion on the women migrants' families by interrelating three key dimensions: migration, emotions and community-based empowerment. This paper argues that albeit the reasons of breaking the tradition as well as a desire for self-achievement, these women juggle to compose their misery and their children's emotional and social behavior. To overcome the drawbacks that affected the traditional family roles of international migrants, who are mothers living abroad, the influence of other social organizations is inevitable. Thus, this study presents a relevant number of interventions based on community development strategies including integrated multi-stakeholders' national strategic plans, high-quality public services and economic empowerment as investments in developing better transnational migrant family environments.

In the seventh paper 'Barriers of financial support towards successful aging among the Participants of Activity Centre for the Older Persons in Malaysia', the study aimed to explore the barriers of financial support experienced by the elderly in pursuing successful aging and it recommends some solutions to overcome those barriers. The paper revealed that the lack of awareness and knowledge, poor family relationships, low household incomes and institutional constraints were among the barriers of financial support faced by the elderly which have led to a lower quality of life and thus hindered progress toward successful aging. Finally, the paper recommends to minimize the reliance of elderly people on family or government by providing them with compatible income sources as well as financial management and planning at an early age. The study also recommends the policymakers to consider the skills and experiences of those elderly people before issuing any policy regarding human capital. The last paper 'Impact of a cyclonic disaster on coastal communities in Bangladesh: Possible community-led interventions towards sustainable disaster recovery', based on $\mathrm{PhD}$ work Emadul Islam and his Supervisor, explores the impacts of the cyclone Aila on a coastal community in Bangladesh, and propose some community-led interventions towards sustainable disaster recovery. The findings revealed the extent and magnitude of the disaster's (Aila) impacts of the community. The study reported that the recovery process was slow owing to such reasons as the short duration of the project, lack of coordination among the recovery intervention, absence of national recovery planning and framework, weak interfacing among the government extension services at the local level, failure to adapt with livelihood transformation, absence of sustainable solution on the problem, e.g. safe drinking water, housing and employment generation, and limited participation opportunity in the recovery program. Most of the cyclone-affected people failed to recover from their losses and damages even after the last ten years. The study proposes a new or overhauled sustainable disaster recovery policy and associated community-led programmatic interventions, e.g. local resource mobilization, community participation, community planning, community partnership, local leadership development and community empowerment.

It has been an honor for us to edit this special issue of the Journal. The articles and the messages contained therein make it amply clear that even though the mosaic of 'community, development and welfare' experiences is changing, the importance of traversing and understanding community and its contexts remains as relevant as ever, and the authors' contributions therefore continue to speak to the key issues of our time.

Happy reading!

\section{Compliance with Ethical Standards}

Conflict of Interest The authors declare that they have no conflict of interest.

Ethical Statement The paper is a desk review and did not involve any data collection from human/animal subjects. As a result, we did not receive any IRB approval for this paper.

\section{References}

Bunkers, S. S. (2003). Community: an emerging mosaic of human becoming. In R. R. Parse (Ed.), Community: a human becoming perspective (pp. 73-96). Massachusetts: Jones and Bartlett publishers, Sudbury.

Carpenter, M., Emejulu, A., \& Taylor, M. (2016). Editorial introduction: what's new and old in community development? Reflecting on 50 years of CDJ. Community Development Journal, 51(1), 1-7.

Kuecker, G., Mulligan, M., \& Nadarajah, Y. (2011). Turning to community in times of crisis: globally derived insights on local community formation. Community Development Journal, 46(2), 245-264.

Parse, R. R. (2003). Community: a human becoming perspective. Massachusetts: Jones and Bartlett publishers, Sudbury.

Publisher's Note Springer Nature remains neutral with regard to jurisdictional claims in published maps and institutional affiliations. 